\title{
DEVELOPMENT OF TEST PROCEDURES
}

Contract No. AT(11-1)-1477

FRACTURE TOUGHNESS OF REACTOR PRESSURE VESSEL STEELS

Sponsor: DRD\&T Program Branch

By

E. J. Ripling and Phillip Crosley

S.

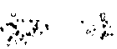

in:

桜:

For the period August 1, 1965 to October 31, 1965

Is sued November 30,1965

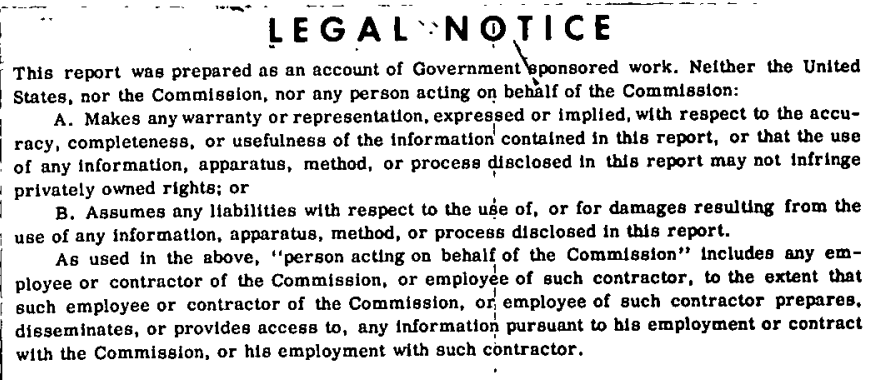




\section{DISCLAIMER}

This report was prepared as an account of work sponsored by an agency of the United States Government. Neither the United States Government nor any agency Thereof, nor any of their employees, makes any warranty, express or implied, or assumes any legal liability or responsibility for the accuracy, completeness, or usefulness of any information, apparatus, product, or process disclosed, or represents that its use would not infringe privately owned rights. Reference herein to any specific commercial product, process, or service by trade name, trademark, manufacturer, or otherwise does not necessarily constitute or imply its endorsement, recommendation, or favoring by the United States Government or any agency thereof. The views and opinions of authors expressed herein do not necessarily state or reflect those of the United States Government or any agency thereof. 


\section{DISCLAIMER}

Portions of this document may be illegible in electronic image products. Images are produced from the best available original document. 


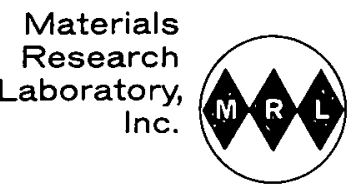

\section{SUMMAR Y}

A double cantilever beam ( $\mathrm{FCB}$ ) testing procedure is being developed to measure the fracture toughness of mild steel. The high ratio of toughness. to yield strength for this material, coupled with the need for small specimens, establishes severe limitations on the methods for measuring plane strain crack toughness. The DCB specimen is most efficient from a size viewpoint; and has the added advantage of providing data for both fracture initiation and arrest.

Because of the inherent difficulties in measuring the fracture tough ness of mild steel, basic information needed for designing DCB specimens can best be obtained from tests on other materials. Work to date has concentrated on epoxy and 7075-T651 aluminum, from which specimens can be inexpensively prepared and for which plane strain crack propagation can be cbtained in small specimens. From these studies the effects of different desicn parameters on the crack propagation direction and on crack arrest capability of the specimen have been determined. Specimen shapes have been developed in which the load required to initiate rapid fracture is independent of the crack length, a feature which makes fracture toughness testing both easier and more reliable.

The information obtained from tests on epoxy and 7075-T65l is now being applied to the specific problem of developing the optimum procedure for testing A $302 \mathrm{~B}$ steel. 


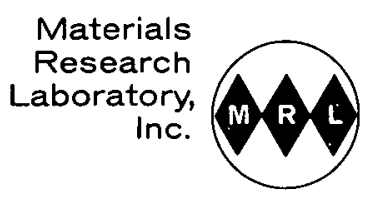

\section{IN T RODUCTION}

The first phase in this project is the development of a fracture toughness test for mild steel. Because the program involves the testing of irradiated samples, a major requirement is that the specimens be as small as possible. The double cantilever beam (DCB) type design, in addition to offering the possibility of small specimen sizes, has the advantage that unstable crack propagation may be initiated without the fracture's extending completely through the specimen. One consequence of this fracture arrest capability is that several fracture toughness measurements may be obtained from a single specimen, and the small specimen size requirement may, therefore, be somewhat relaxed. More important, however, is the fact that fracture toughness for crack arrest as well as for the initiation of rapid fracture can be evaluated. Fracture arrest data are particularly important for materials like mild steel. In a welded structure, the onset of rapid fracture would be expected to occur in a weld region (since this is the most likely location for a large flaw) and a design criterion should be based on the ability of the mild steel base metal to arrest the expanding crack.

Although the DCB specimen is not at present as completely characterized as other test specimens, the advantages which it offers were felt to justify the investment in developing an optimum test procedure. Work to date has been concentrated on two materials, epoxy and 7075-T651 aluminum, in order to obtain information about the DCB specimen which could be trans-: ferred to the specific problem of devising a test procedure for mild steel.

\section{DESCRIPTION OF THE DCB SPECIMEN}

To illustrate the general features of the DCB design, a specimen developed for testing 7075-T651 aluminum is shown in Fig. 1. Fig. 2 indicates the notation used for specifying specimen dimensions. The load, $P$, applied through pins inserted in the loading holes, causes the crack to extend along the median plane of the sample. The deflection ( 5 ) is measured across the opposing surfaces of the rectangular cut-out. A. V-shaped wing enables a starting crack to be produced at the beginning of a test, obviating the need for pre-cracking by fatigue. The side grooves are used to promote plane strain at the crack front and to assist in maintaining the crack within the desired plane. 


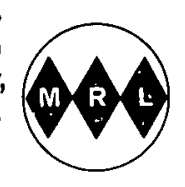

\section{CONTROL OF CRACK PROPAGATION DIRECTION}

The taper angle ( $\theta$ and the groove depth act together in controlling the crack propagation direction. With small angles and shallow grooves the crack veers out of the median plane commonly breaking off an arm of the specimen. For an isotropic material (epoxy), a taper angle of $\theta=40^{\circ}$ was sufficient to cause the crack to run straight in the absence of side grooves. With the 7075-T651 aluminum the testing direction was a critical factor. Cracks propagated parallel to the rolling direction ran straight with no side grooves and constant beam height of $\underline{h}=1.0 \mathrm{inch}$. When $0.5 \mathrm{inch}$ plate was tested perpendicular to the rolling direction using a specimen with $\theta=25^{\circ}$, side grooves giving $\left(b_{n} / b\right)=0.8$ were needed to control the crack direction. With a smaller taper angle deeper grooves were required; with less deep grooves a larger taper angle was required.

\section{CONSTANT COMPLIANCE CHANGE}

The specimen taper may be designed so that the load at the onset of rapid fracture is independent of the crack length. For a given crack length, a, the deflection $\delta$ and the load $P$ are related by a proportionality constant $\bar{C}$, the specimen compliance

$$
\delta=P C
$$

the crack extension force $\mathscr{L}$ is defined by

$$
p=\frac{p^{2}}{2 b}\left(\frac{d C}{d a}\right)
$$

Rapid fracture occurs when the crack extension force attains a critical value which, for plane strain conditions at the crack front, is denoted as $\&$. Evaluation of the plane strain fracture toughness \& requires a measurement of the load $P$ corresponding to the onset of rapid fracture and a knowledge of $\mathrm{dC} / \mathrm{da}$. In general, $\mathrm{dC} / \mathrm{da}$ depends on the crack length, and its evaluation by experimental calibration involves obtaining an analytic expression for an emperical curve. In addition, the crack length a at the onset of rapid frac-. ture must be accurately determined in each test. If a sample is designed, however, so that $\mathrm{dC} / \mathrm{da}$ is constant, the critical load $\mathrm{P}$ at the onset of rapid fracture is likewise independent of the crack length, and measurement of the 
crack length in an individual test is no longer required. Moreover, because $C$ varies linearly with $\underline{a}$, an experimental calibration of a given specimen is easier and more reliable.

If the DCB specimen is treated analytically as a pair of cantilever beams, elementary beam deflection theory can be used to obtain the expression

$$
\frac{d C}{d a}=\frac{8}{E b}\left(\frac{1}{h}+\frac{3 a^{2}}{h^{3}}\right)
$$

where $E$ is Young's modulus, and $\underline{h}$ is the beam height at a distance $\underline{a}$ from the point of load application. Eq. 3 can be used in designing constant compliance change specimens. The expression (Eq. 3) proved to be in good agreement with experiment. The samples shown in Fig. 1 were designed with a linear taper approximating the contour defined by

$$
\frac{1}{h}+\frac{3 a^{2}}{h^{3}}=4
$$

With this design the variation in the load $P$ was within ten percent with crack lengths in the range 1.3 to 3 or more inches. With a specimen machined

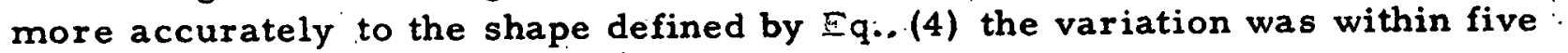
percent and showed no systematic deviation, suggesting that the fluctuation was traceable to the material rather than to the specimen design.

\section{CRACK ARREST CAPABILITY}

As has been indicated, the crack arrest capability of the DCB specimen is one of its principal advantages. The possibility of obtaining crack arrests depends both on the material being tested and on the design of the specimen. In testing epoxy, cracks were propagated in jumps of $1 / 8$ inch or less, but in early tests on 7075-T651 aluminum the first application of the load commonly produced cracks which extended completely through the specimen. The high strain rate sensitivity of mild steel suggests that crack instability here may be an even greater problem. These considerations pointed out the need for some method of evaluating the crack arrest capability of a given specimen design.

A measure of the crack arrest capability is the rate at which the crack extension force $(\not)$ decreases as a crack propagates. For a constant compliance 
change specimen the following expression (which is derived in the appendix) can be obtained.

$$
\frac{\mathscr{g}_{I c}}{\mathscr{g}_{a}}=\left[1+\frac{a-a_{1}}{a_{1}}\right]^{2}
$$

In this expression $\mathscr{B}_{\mathrm{Ic}}$ is the crack extension force to initiate unstable propagation of a crack with an initial length $\underline{a}_{1} \cdot \mathscr{H}_{\mathrm{a}}$ is the available crack extension. force when the crack has extended to a length a under fixed-grip conditions. Fig. 3, obtained from Eq. (5), shows the value of $\&_{a} / \&_{I f}$ as a function of the crack length, a, for different initial crack lengths. Fig. 3 indicates that the shorter the initial crack length the more rapid is the drop in the available $\&$ and hence the $g r e a t e r$ is the crack stability. This result was exploited in testing 7075-T651 aluminum by moving the apex of .the $V$-shaped wing to a position directly in line with the loading holes (as may be seen in Fig. 1). With this arrangement crack arrests were consistently obtained. Moreover, a starting crack, induced by fatigue was not needed, even though the load required a crack in the saw-cut wing was almost twice that required to propagate an existing crack.

A prediction, implicit in Eq. (5) is that the crack stability is independent of the specimen shape provided that the condition of constant compliance change is satisfied. Experience with different specimens, however, indicated that by decreasing the taper angle the crack arrest capability was enhanced. This behavior suggested that a lack of rigidity of the testing arrangement is a significant factor. The crack does not propagate with a constant value of the deflection $\delta$, but rather under constant displacement $D$ which is the sum of $\delta$ and an elastic extension in the testing machine. Defining the compliance of the testing machine $C_{M}$ by

$$
C_{M} P=D-\delta
$$

the following expression (derived in the appendix) can be obtained

$$
\frac{g_{I c}}{g_{a}}=\left[1+\frac{a-a_{1}}{a_{1}}\left(\frac{1}{1+\frac{C_{M}}{C_{1}}}\right)\right]^{2}
$$




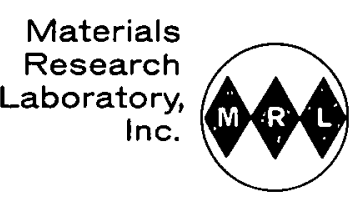

where $C_{1}$ is the specimen compliance at the initial crack length $a_{1}$. For a perfectly rigid machine $\left(C_{M}=0\right)$ the above expression reduces to Eq. 6 . However, if the machine compliance is large enough to be a significant factor, it can be seen that specimens with higher values of $\mathrm{C}_{1}$ (i.e., specimens with lower taper angles) should possess greater crack stability in agreement with experimental observation. Because of the need to provide maximum crack arrest capability for testing mild steel, provisions are being made for a very rigid testing arrangement.

\section{CURRENT STATUS OF TEST DEVELOPMENT}

One factor which up to this point has been ignored is the length of the specimen. When the crack front approaches the end of the sample, the compliance increases rapidly with increasing a, and Eq. (3) ceases to give an accurate approximation of $\mathrm{dC} / \mathrm{da}$. This excessive increase in compliance is produced by a hinging action of the end portion of the specimen. The requirement that the end of the specimen be rigid places a lower limit on the length, and restricts the range of crack lengths over which fracture toughnes measurements can be readily or reliably obtained. At the present time, epoxy specimens four inches long have proved successful. With specimens of this size straight cracks could be propagated over a range of crack lengths of $1-1 / 2$ inches or more. In this range several crack arrests were obtained, and the condition of constant compliance change was maintained.

A possible method for reducing the specimen size is the use of an attachment which restricts the bending of the uncracked portion of the sample; Measurements could then be made with the crack front closer to the end of the sample. If the attachment were used also to modify the specimen compliance, the height requirement to obtain constant compliance change could be reduced. Tests will be conducted to study the feasibility of using attachments.

Fracture toughness testing of mild steel is expected to introduce new problems, the main source of which is the high value of fracture toughness relative to the yield strength. A large specimen width, $\underline{b}$, will have to be employed to obtain plane strain conditions at the crack front, or, alternatively, the tests may have to be conducted at low temperatures. Rigid specimens with deep side grooves will be required to prevent plastic bending. The requirement of rigid specimens combined with the strain rate sensitivity of mild steel will make crack arrest more difficult. It is felt, however, that the understanding of the effect of design variables obtained from tests on epoxy and aluminum, provide the basis for systematic approach to the design of a fracture toughnes.s test for mild steel. Work on mild steel is now under way. 


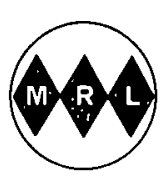

\section{A PPENDIX}

The crack arrest capability of a specimen design is determined by the rate at which the crack extension force, $\mathcal{L}$, decreases as the crack extends. If the specimen compliance is known as a function of the crack length, the crack arrest capability can be assessed analytically. The derivation for a constant compliance change specimen is given below.

At a crack length a, measured from the line of action of the load, the specimen compliance, $\mathrm{C}_{\mathrm{a}}$, is given by

$$
c_{a}=\int_{0}^{a}\left(\frac{d C}{d a}\right) d a
$$

Consider a sample with constant compliance change $\mathrm{dC} / \mathrm{da}=\mathrm{C}^{\prime}$ for a $>\mathrm{a}_{0_{0}}$ Then

$$
c_{a}=C_{0}+C^{\prime}\left(a-a_{0}\right)
$$

Where $C_{O}$ is the specimen compliance when the crack length is a ${ }_{0}$ It is convenient to write

$$
c_{0}=C^{\prime}\left(a_{0}-\alpha\right)
$$

so that the deviation from constant compliance change for a $<a$ is accounted for by shifting the origin from which the crack length is measured. (In practice a corresponds to the length of the straight portion of the specimen needed to accomodate the loading holes, and $\mathrm{C}_{0}<\mathrm{C}^{\prime} \mathrm{a}_{0^{\circ}}$ In this case $a$ is a positive number smaller than $a_{0} \cdot 1$

The crack extension force is given by

$$
\mathscr{L}=\frac{\mathrm{p}^{2}}{2 \mathrm{~b}} \frac{\mathrm{dC}}{\mathrm{da}}
$$

or in terms of the displacement $\delta$,

$$
\xi=\frac{\delta^{2}}{2 b_{n}} \frac{1}{c^{2}} \frac{d c}{d a}
$$


For a crack length at $a_{1}, a_{1}>a_{0}$ :

$$
k_{1}=\frac{\delta_{1}^{2}}{2 b_{n}} \frac{c^{\prime}}{c_{1}^{2}} \text {. }
$$

and at $a_{2}, a_{2}>a_{1}$ :

$$
\Sigma_{2}=\frac{\delta_{2}^{2}}{2 b_{n}} \frac{c^{\prime}}{c_{2}^{2}}
$$

Combining Eqs. (6) and (7) leads to

$$
\sqrt{\frac{\xi_{1}}{\varepsilon_{2}}}=\frac{\delta_{1}}{\delta_{2}} \frac{\mathrm{C}_{2}}{\mathrm{C}_{1}}
$$

Upon making the substitutions

$$
c_{2}=c_{1}+C^{\prime}\left(a_{2}-a_{1}\right)
$$

and,

$$
c_{1}=c^{\prime}\left(a_{1}-\alpha_{1}\right)
$$

Eq. (8) becomes

$$
\frac{\mathscr{L}_{1}}{\boldsymbol{g}_{2}}=\frac{\delta_{1}}{\delta_{2}}\left[1+\frac{a_{2}-a_{1}}{a_{1}-\alpha}\right]
$$

When $\mathscr{H}=\mathscr{H}$ unstable propagation of a crack of length a, is initiated. When the crack has extended by an amount $\Delta a$ to a position $a_{2}$ under fixed grip conditions $\left(\delta_{1}=\delta_{2}\right)$ the available crack extension force $\mathscr{Z}_{a}$ is given by Eq. (11) as

$$
\frac{\xi_{I_{c}}}{k_{a}}=\left[1+\frac{a}{a_{1}-\alpha}\right]^{2}
$$




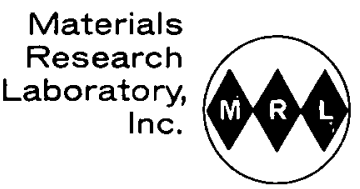

Taking $\alpha=0$ does not alter the general behavior predicted by Eq. (12) and for typical sample designs leads only to a slight underestimation of the crack arrest capability. Hence, it is convenient to write Eq. (12) as

$$
\frac{\xi_{1}}{\xi_{a}}=\left[1+\frac{\Delta a}{a_{1}}\right]^{2}
$$

Under normal testing conditions the fixed grip assumption $\delta_{1}=\delta_{2}$ is not rigorously satisfied. The testing apparatus suffers an elastic displacement, which may be related to the applied load by defining a testing machine compliance $C_{M^{*}}$. The crack propagates with a constant displacement $I$ which is the sum of the specimen displacement $\delta$ and the machine deflection $\mathrm{PC}_{\mathbf{M}^{\cdot}}$ For a crack of length

$$
\Gamma=\delta_{1}+P_{1} C_{M}
$$

and for a crack of length $a_{2}$ '

$$
I=\delta_{2}+P_{2} C_{M}
$$

Combining Eqs. (14) and (15) gives

$$
\delta_{1}+P_{1} C_{M}=\delta_{2}+P_{2} C_{M}
$$

or,

$$
P_{1} C_{1}+P_{1} C_{M}=P_{2} C_{2}+P_{2} C_{M}
$$

and,

$$
\frac{P_{1}}{P_{2}}=\frac{C_{2}+C_{M}}{C_{1}+C_{M}}
$$

From Eq. (3)

$$
\frac{P_{1}}{P_{2}}=\sqrt{\frac{g_{1}}{g_{2}}}
$$


Materials

Research

Laboratory

Inc.

Combining Eqs. (16) and (17) and substituting the proper expression for $C_{1}$ and $C_{2}$ (Ens. $(9)$ and $(10)$ ) leads to

$$
\frac{\xi_{1}}{\beta_{2}}=\left[1+\frac{a_{2}-a_{1}}{a_{1}-\alpha}\left(\frac{1}{1+C_{M} / C_{1}}\right)\right]^{2}
$$

Using the same interpretation as in obtaining Eq. (13) gives

$$
\frac{\mathscr{I}_{\mathrm{Ic}}}{\mathscr{g}_{\mathrm{a}}}=\left[1+\frac{\Delta \mathrm{a}}{\mathrm{a}_{1}}\left(\frac{1}{1+\mathrm{C}_{M^{/ C_{1}}}}\right)\right]^{2}
$$

$-9-$ 


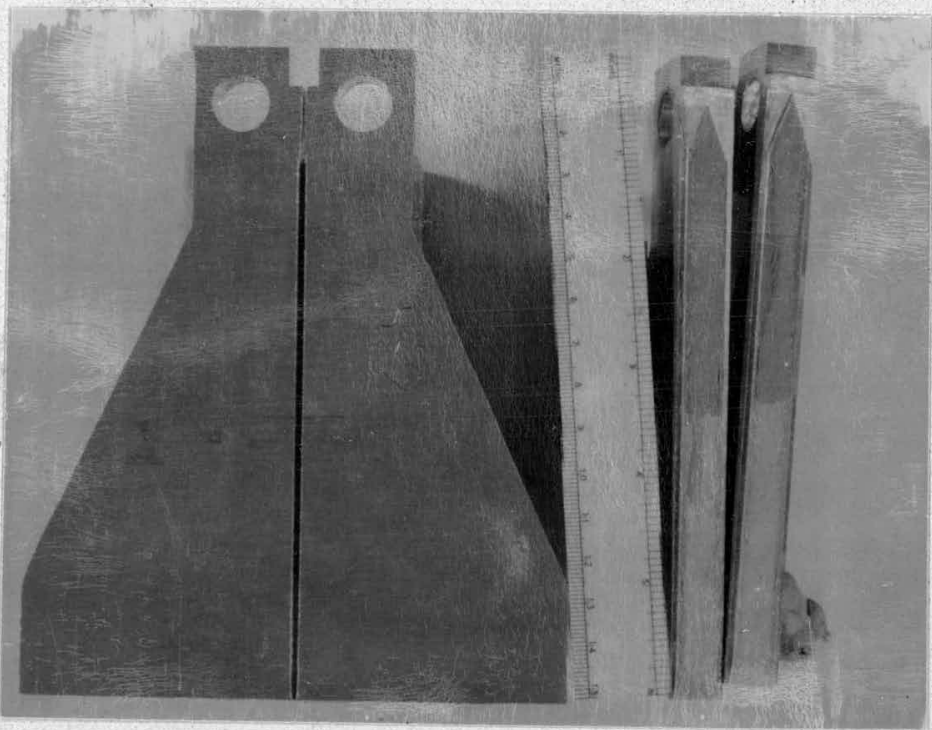

Fig. 1 DCB SPECIMENS OF 7075-T651 ALUMINUM BEFORE AND AFTER TESTING. THE DARK PORTION OF THE FRACTURE SURFACE IS AN OIL STAIN USED TO MARK THE CRACK LENGTH. 

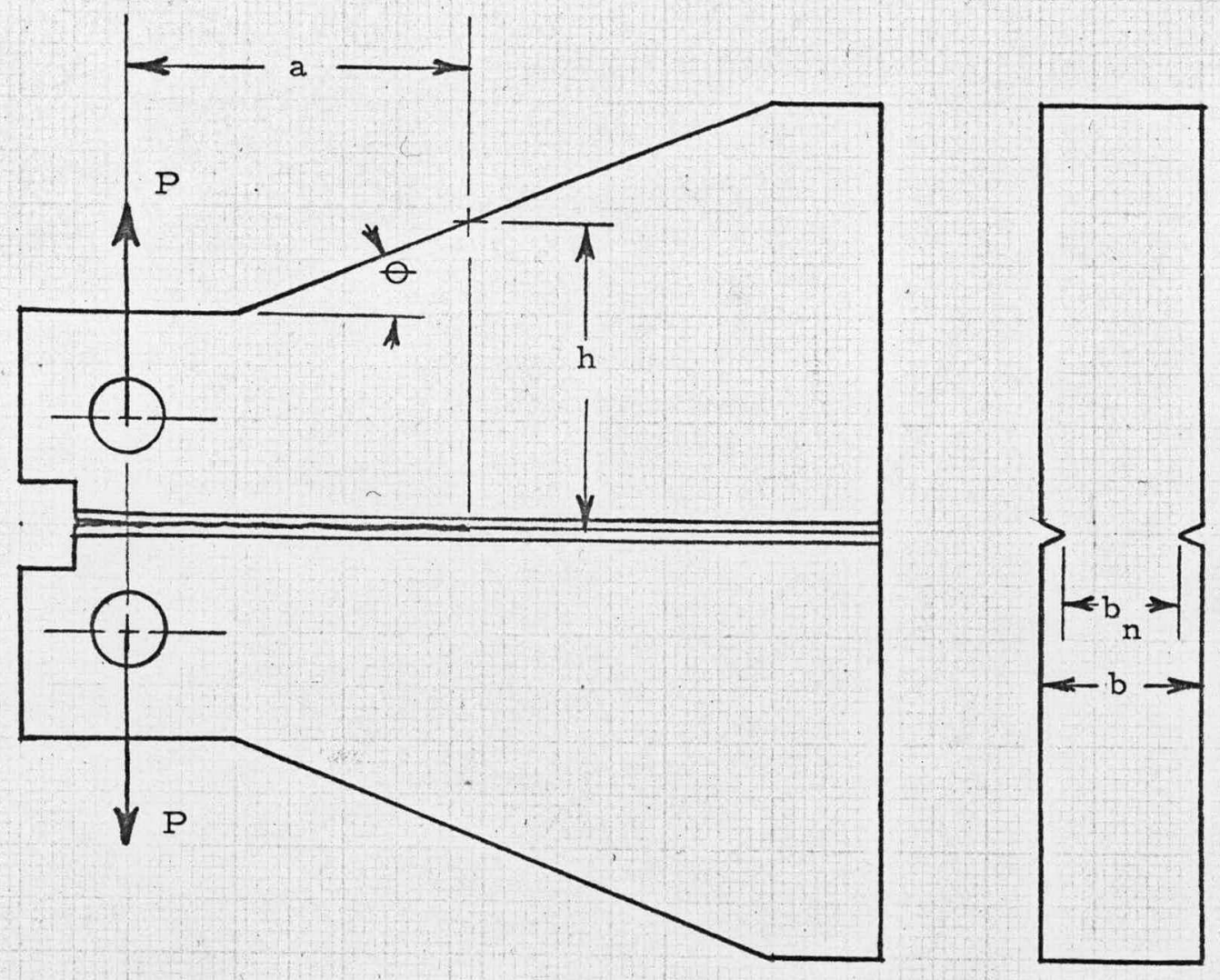

Fig. 2 NOTATION USED IN DESCRIBING THE DCB SPECIMEN. 


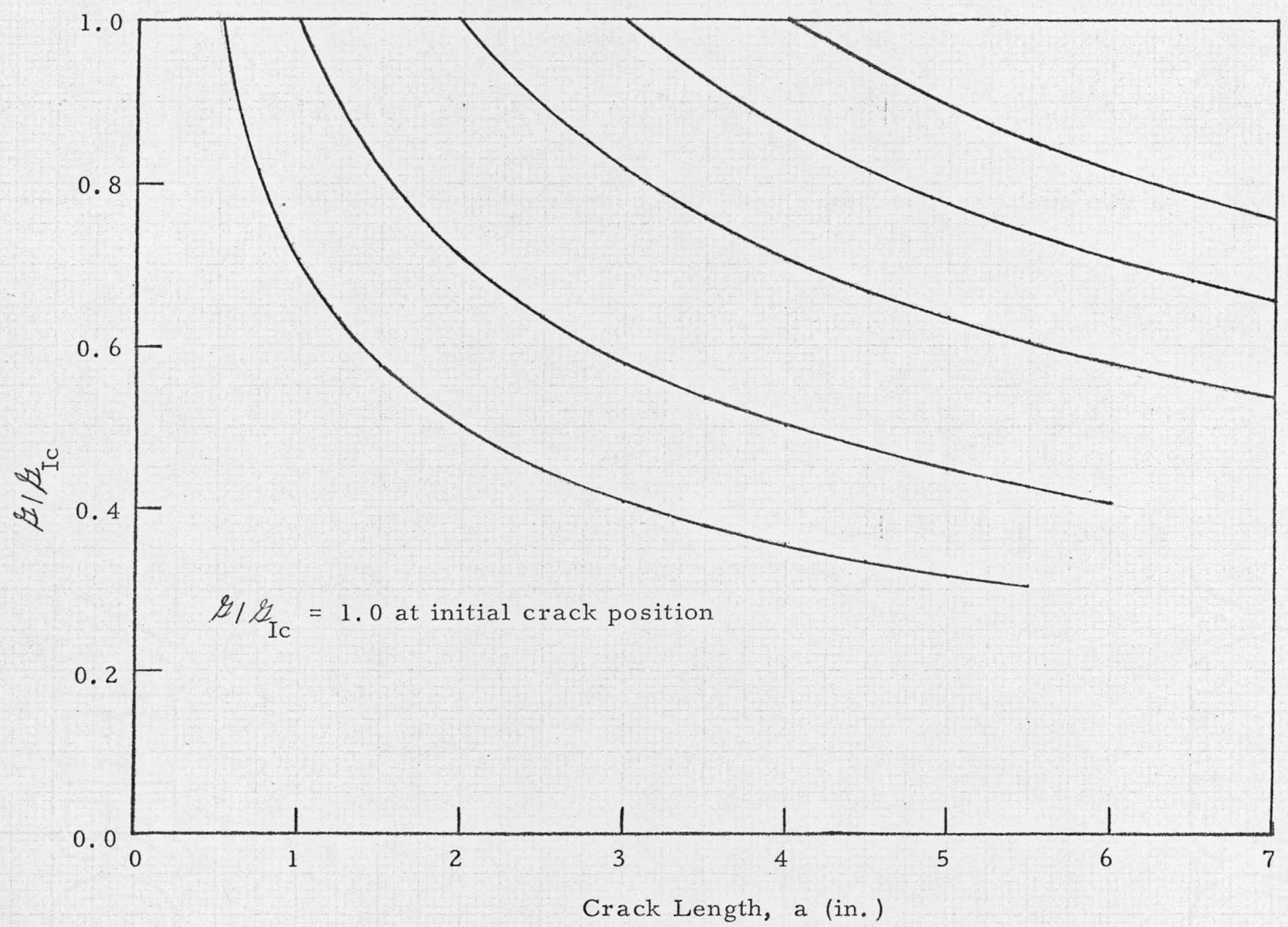

Fig. 3 DEPENDENCE OF \&/ \& ON CRACK LENGTH FOR DIFFERENT INITIAL CRACK POSITIONS (FIXED-GRIP CONDITIONS). 